\title{
Profile of the Brazilian scientific production in multiple sclerosis
}

\author{
C.R. Araujo, \\ M.A. Moreira and \\ M.A. Lana-Peixoto
}

\author{
Centro de Investigação em Esclerose Múltipla de Minas Gerais, \\ Departamento de Oftalmologia, Faculdade de Medicina, \\ Universidade Federal de Minas Gerais, Belo Horizonte, MG, Brasil
}

\begin{abstract}
Correspondence
M.A. Lana-Peixoto

Rua Padre Rolim, 769, Sala 1301

31130-090 Belo Horizonte, MG

Brasil

E-mail: lanapma@uol.com.br

$\ldots \ldots \ldots \ldots \ldots \ldots \ldots$
\end{abstract}

Received December 12, 2005 Accepted May 29, 2006

\begin{abstract}
This paper analyzes the profile of the Brazilian output in the field of multiple sclerosis from 1981 to 2004. The search was conducted through the MEDLINE and LILACS databases, selecting papers in which the term "multiple sclerosis" was defined as the main topic and "Brazil" or "Brasil" as others. The data were analyzed regarding the themes, the state in Brazil and institution where the papers were produced, the journals where the papers were published, journal's impact factor, and language. The search disclosed 141 documents (91 from MEDLINE and LILACS, and 50 from LILACS only) published in 44 different journals ( 23 of them MEDLINE-indexed). A total of 111 documents were produced by 17 public universities, 29 by 3 private medical schools and 1 by a non-governmental organization. There were 65 original contributions, 37 case reports, 20 reviews, 6 $\mathrm{PhD}$ dissertations, 5 guidelines, 2 validation studies, 2 clinical trials, 2 chapters in textbooks, 1 Master of Science thesis, and 1 patient education handout. The journal impact factor ranged from 0.0217 to 6.039 (median 3.03). Of 91 papers from MEDLINE, 65 were published by Arquivos de Neuro-Psiquiatria. More than $90 \%$ of the papers were written in Portuguese. São Paulo was the most productive state in the country, followed by Rio de Janeiro, Minas Gerais and Paraná. Eighty-two percent of the Brazilian output came from the Southeastern region.
\end{abstract}

Key words - Multiple sclerosis

- Scientific production

- Brazil

\section{Introduction}

Multiple sclerosis (MS) is a chronic immuno-mediated inflammatory and demyelinating disease of the central nervous system, characterized by a progressive clinical course leading to physical disability. Despite intensive efforts to determine the nature of the disease, no etiologic agent has been identified. In the last two decades, investigators have taken advantage of the sophisticated technological advances in genetics, molecular medicine, pathology, and imaging of the central nervous system to promote a tremendous change in the understanding of the nature, pathogenesis, clinical features, diagnosis, and treatment of the disease. Clinical and basic research journals have published a vast amount of papers by researchers from all continents, showing that the search for better knowledge of the disease has become a world concern.

Recently, we looked at the geographical distribution of MS publications from 1990 to 1999 using the MEDLINE database and noticed a regular growth in the number of papers during this period (1). This trend was 
observed in most countries and on all continents. The largest number of papers in this field came from the United States, Italy, United Kingdom, and Germany. Canada, Brazil and Mexico followed the US on the American continent. Although most papers have been produced by affluent countries with high gross domestic product per capita (GDPpc), we observed that a high GDPpc is not always a positive predictive factor for the highest ranking positions (2). Brazil is an example of this observation since it has one of the lowest GDPpc among all the countries studied but still had a better performance than countries with four times as high a GDPpc such as Switzerland, Norway, Belgium, and Australia (2).

In the present paper, we describe the profile of the scientific output in MS in Brazil, assessing the type of document, its theme, journal impact factor, and the location and nature of the institutions - whether public or private - where MS research was carried out and published. The results of this study may shed some light on factors that influence scientific output on MS in Brazil. Additionally they may suggest ways to turn the Brazilian scientific production more diffuse and visible.

\section{Methods}

The search was conducted on the Internet using the MEDLINE and the Latin American and Caribbean Health Science Literature Database (LILACS) databases. The LILACS database was included in order to add papers from Latin America and Caribbean countries which might not be present in the MEDLINE database.

In order to avoid duplication, the documents indexed in both databases were identified and counted only once.

\section{MEDLINE database}

MEDLINE was accessed through the
National Library of Medicine website (http:// www.ncbi.nlm.nih.gov/PubMed/medline. html). The search was performed in the advanced-search option. In the search strategy we entered the term "multiple sclerosis" in the field "MeSH Major Topic" to select papers in which multiple sclerosis was the main topic discussed. Both 'Brazil' and 'Brasil', separated by the preposition "OR", were typed in the field "affiliation" to select Brazilian papers. This field reflects the institutional affiliation of the first author of the article.

\section{LILACS database}

The LILACS database was accessed through the BIREME website (http:/www. bireme.org). The search strategy was the same as described for the MEDLINE database. We considered all kinds of documents indexed in the LILACS database (theses, books, chapters in books, abstracts of meetings or conferences, technical-scientific reports, original papers, short communications, and case reports).

The data were analyzed in relation to the indexing database (MEDLINE and LILACS), the state in which the Institution is located, type of publication, journal title, impact factor of the journal, language of publication, and the type of the institution the first author was affiliated with (whether public or private).

The impact factor of the journal was obtained from the Journal of Citation Report published by the Institute for Scientific Information (ISI) (3) for the year 2003 and from the Latin American and Caribbean Center on Health Science Information (http:// www.bireme.org) for the year 2004.

\section{Results}

The search identified 141 documents in the field of MS produced in Brazil from 1981 to 2004. There were 91 papers in 
MEDLINE published in 23 different journals and 117 documents in the LILACS database published in 23 journals (Table 1). Sixty-seven papers appeared in both databases and 50 documents appeared in LILACS but not in MEDLINE. The earliest paper found in MEDLINE was published in 1982 and the earliest found in LILACS was published in 1981.

The Brazilian documents published during the period comprised 65 original publications, 37 case reports, 20 reviews, $6 \mathrm{PhD}$ dissertations, 5 guidelines, 2 validation studies, 2 clinical trials, 2 chapters in textbooks, 1 Master of Science thesis, and 1 patient education handout. The mean publication rate was 5.9 per year. In spite of some yearly oscillations, there was an increase in publications with time as shown in Figure 1. From 1981 to 1985 Brazilian investigators produced 10 papers on MS, whereas from 2000 to 2004 the output was 53 . The publication growth in the field of MS is similar to that of Brazilian scientific output in medical sciences which increased from 1889 papers in 1981 to 10,555 in 2001 (4).

Brazilian investigators published their papers in 44 different journals - 22 Brazilian and 22 foreign journals - with an impact factor (IF) ranging from 0.0217 to 6.039 . Only 2 of the Brazilian journals - Arquivos de Neuro-Psiquiatria, IF 0.3161, and Brazilian Journal of Medical and Biological Research, IF 0.74 - are indexed in the MEDLINE database. Sixty-five papers were published in the Arquivos de Neuro-Psiquiatria and only 1 in the Brazilian Journal of Medical and Biological Research. The remaining 25 papers in MEDLINE were published in foreign journals.

The State of São Paulo was the most productive state in the country, accounting for 73 papers (52\%), followed by the States of Rio de Janeiro (30 papers, 21\%), Minas Gerais and Paraná (12 papers, $8.5 \%$ each), Rio Grande do Sul (7 papers, 5\%) and Federal District with 3 papers, Pernambuco with
Table 1. Journals in which Brazilian papers on multiple sclerosis were published during the period from 1981 to 2004.

\begin{tabular}{|c|c|c|c|c|}
\hline Journal & Impact factor & Database & No. of papers & $\%$ \\
\hline Arq Neuro-Psiquiatr & 0.3161 & MEDLINE, LILACS & 65 & 46 \\
\hline Rev Bras Neurol & NA & LILACS & 9 & 6 \\
\hline Rev Paul Med & $0.1654^{\star}$ & LILACS & 4 & 3 \\
\hline Acta AWHO & NA & LILACS & 3 & 2 \\
\hline Rev Bras Med Otorrinolaringol & NA & LILACS & 3 & 2 \\
\hline J Neurol Neurosurg Psychiatry & 3.035 & MEDLINE & 2 & 1 \\
\hline Multiple Sclerosis & 2.645 & MEDLINE & 2 & 1 \\
\hline Neurologia & 0.642 & MEDLINE & 2 & 1 \\
\hline Acta Neurol Scand & 1.226 & MEDLINE & 2 & 1 \\
\hline Rev Imagem & NA & LILACS & 2 & 1 \\
\hline Neurobiologia & NA & LILACS & 2 & 1 \\
\hline Rev AMRIGS & NA & LILACS & 2 & 1 \\
\hline Neurology & 5.678 & MEDLINE & 1 & 1 \\
\hline Neuroepidemiology & 1.762 & MEDLINE & 1 & 1 \\
\hline Biol Psychiatry & 6.039 & MEDLINE & 1 & 1 \\
\hline Brain Dev & 1.231 & MEDLINE & 1 & 1 \\
\hline Arch Med Res & 1.277 & MEDLINE & 1 & 1 \\
\hline Braz J Med Biol Res & 0.74 & MEDLINE, LILACS & 1 & 1 \\
\hline Immunol Invest & 0.886 & MEDLINE & 1 & 1 \\
\hline Rev Laryngol Otol Rhinol & NA & MEDLINE & 1 & 1 \\
\hline Cytokine & 2.183 & MEDLINE & 1 & 1 \\
\hline Brain Res Mol Brain Res & NA & MEDLINE & 1 & 1 \\
\hline Rev Neurol & 0.201 & MEDLINE & 1 & 1 \\
\hline J Interferon Cytokine Res & 2.12 & MEDLINE & 1 & 1 \\
\hline J Clin Exp Neuropsychol & 1.273 & MEDLINE & 1 & 1 \\
\hline Rheumatol Int & 1.013 & MEDLINE & 1 & 1 \\
\hline J Pediatr & 2.913 & MEDLINE & 1 & 1 \\
\hline Curr Opin Clin Nutr Metab Care & 2.353 & MEDLINE & 1 & 1 \\
\hline J Voice & 0.595 & MEDLINE & 1 & 1 \\
\hline BioDrugs & 2.277 & MEDLINE & 1 & 1 \\
\hline Rev Hosp Clin Fac Med Univ SP & $0.0707^{*}$ & LILACS & 1 & 1 \\
\hline Rev Bras Clin Ter & NA & LILACS & 1 & 1 \\
\hline Rev Bras Oftalmol & NA & LILACS & 1 & 1 \\
\hline Femina & NA & LILACS & 1 & 1 \\
\hline Esc Anna Nery Ver Enferm & NA & LILACS & 1 & 1 \\
\hline Arq Bras Oftalmol & $0.1333^{*}$ & LILACS & 1 & 1 \\
\hline Rev Med São Vicente de Paulo & NA & LILACS & 1 & 1 \\
\hline Radiol Bras & $0.0662^{*}$ & LILACS & 1 & 1 \\
\hline Rev Bras Reumatol & NA & LILACS & 1 & 1 \\
\hline J Bras Patol & $0.0217^{*}$ & LILACS & 1 & 1 \\
\hline Rev Bras Med & NA & LILACS & 1 & 1 \\
\hline Arq Inst Penido Brunier & NA & LILACS & 1 & 1 \\
\hline Reun Neurofisiol Clin & NA & LILACS & 1 & 1 \\
\hline Rev Bras Patol Clin & NA & LILACS & 1 & 1 \\
\hline
\end{tabular}

Not included $6 \mathrm{PhD}$ dissertations, 2 chapters in textbooks, 1 Master of Science thesis, and 1 patient education handout, all of them indexed only by the LILACS database. NA $=$ not available. All impact factors were from ISI-Thomson except those marked with an asterisk, which were from BIREME. 


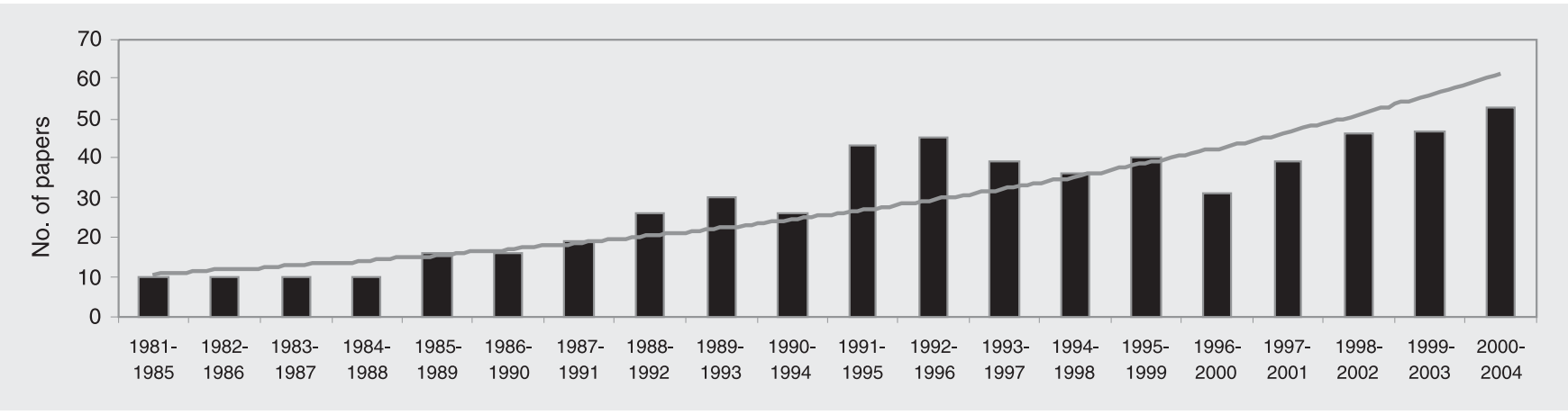

Figure 1. Growth of papers published on multiple sclerosis in Brazil. The line indicates the trend of growth.

Table 2. Origin of the Brazilian output on multiple sclerosis during the period from 1982 to 2004.

\begin{tabular}{lcrc}
\hline State & $\begin{array}{c}\text { Documents } \\
\text { N (\%) }\end{array}$ & \multicolumn{2}{c}{ Institutions } \\
\cline { 3 - 4 } & & Public & Private/NGO \\
\hline São Paulo & $73(52)$ & 50 & 23 \\
Rio de Janeiro & $30(21)$ & 29 & 1 \\
Minas Gerais & $12(8.5)$ & 12 & 0 \\
Paraná & $12(8.5)$ & 8 & 4 \\
Rio Grande do Sul & $7(5)$ & 6 & 1 \\
Distrito Federal & $3(2)$ & 3 & 0 \\
Pernambuco & $2(1)$ & 2 & 0 \\
Espírito Santo & $1(1)$ & 0 & 1 \\
Ceará & $1(1)$ & 111 & 0 \\
Total & 141 & & 30 \\
\hline
\end{tabular}

Source: CNPq, Plataforma Lattes. NGO = non-governmental organization.

Table 3. Themes addressed by Brazilian multiple sclerosis documents.

\begin{tabular}{lcc}
\hline Theme & N & $\%$ \\
\hline Clinical aspects & 47 & 33 \\
Immunology & 24 & 17 \\
Neurobiology/Neurophysiology & 16 & 11 \\
Neuropsychology & 13 & 9 \\
Epidemiology & 12 & 9 \\
Treatment & 12 & 9 \\
Diagnosis review & 6 & 4 \\
Experimental autoimmune encephalomyelitis & 4 & 3 \\
Genetics & 2 & 1 \\
Imaging & 2 & 1 \\
Symptomatic management & 1 & 1 \\
History & 1 & 1 \\
Education & 1 & 1 \\
\hline
\end{tabular}

2, whereas the State of Espírito Santo and Ceará contributed with 1 paper each. Regarding the geographical regions of the country, $82.5 \%$ of the papers were produced in the Southeast, $13.5 \%$ in the South, $2 \%$ in the Northeast, and $2 \%$ in the West.

Of the 141 documents, 111 were produced in 17 public universities (5 State Universities and 12 Federal Universities), 29 in 3 private medical schools, and 1 in a nongovernmental organization, as shown in Table 2 .

Ninety-one documents (65\%) were written in Portuguese, 48 (34\%) in English, 1 in French, and 1 in Spanish. Of the 91 papers from MEDLINE, 48 were written in English, 41 in Portuguese, 1 in French, and 1 in Spanish. On the other hand, all of the 50 documents exclusively found in the LILACS database were written in Portuguese. Portuguese was also the language of $40(65 \%)$ of 65 papers published by the Arquivos de Neuro-Psiquiatria. Of the remaining 25 papers published by this journal, 24 (37\%) were written in English and 1 (1\%) in French. The single paper published by the Brazilian Journal of Medical and Biological Research was written in English.

Brazilian documents addressed a diversity of themes in the field of MS, the vast majority of them dealing with clinical and immunological aspects of the disease, as shown in Table 3. 


\section{Discussion}

Scientific publishing is an intrinsic and important part of the process of disseminating scientific knowledge and innovation. The use of the scientific literature as a measure of research activity has acquired great importance in the assessment of the production and utilization of scientific information. The MEDLINE database was chosen because it is a biomedical website often accessed by the international scientific community and a frequently used tool for studies of scientific production (5-9).

However, due to some inherent limitations of the available databases, the accuracy of the data cannot be fully relied on $(10,11)$. The present paper illustrates some of these shortcomings very clearly. In the search strategy, for example, the field "affiliation" has not been designed necessarily as an indication of the place where the research was conducted, though, in most cases, it could indicate it. This field of the search inquiry indicates the geographical location of only the first author when this information has been supplied in the document.

It has been observed that investigators have not been indicating their academic affiliation in a standardized and informative way and an inappropriate indication of these data not only makes it difficult for the author to be reached by those interested in the research, but also prevents adequate registration of the paper in the database and other information systems (12). In an attempt to reduce the impact of bias regarding the country of origin of the first author and to avoid missing papers due to non-standardized information in this field, we used both the "Brasil" and "Brazil" spellings. We took into account only the first author's institution and address, even in documents coauthored by investigators in different states. As a result, if Brazilian researchers were not the first authors in international co-authored papers, the work might not be considered.
Another methodological limitation concerns the field "MeSH Major Topic" in the search strategy of the MEDLINE database. By the use of this strategy papers on MS were cited only if the term "multiple sclerosis" was clearly defined by their authors as their main topic. The search mechanisms of the LILACS database contain similar limitations.

Our previous study on the geographical distribution of MS papers in the world (1) showed a marked disparity across different countries. Likewise, the present paper demonstrates huge disparities in different geographical areas of Brazil. Most Brazilian papers come from São Paulo, Rio de Janeiro and Minas Gerais in Southeastern Brazil. Investigators in Southeastern and Southern Brazil have produced over $90 \%$ of the total scientific output in the field of MS. This finding may be explained by the fact that over $80 \%$ of the research groups in Brazil are located in these areas of the country (13).

The present study also showed that the vast majority of the documents in the field of MS in Brazil have been produced by investigators working at public medical schools. Only 3 private medical schools and 1 nongovernmental organization have contributed to the Brazilian output in this field.

Arquivos de Neuro-Psiquiatria, the official journal of the Brazilian Academy of Neurology and a MEDLINE-indexed periodical with an IF of 0.316 , has been the leading journal used by Brazilian investigators in the field of MS to publish their papers. Only a small number of papers have been published in other MEDLINE-indexed journal whereas a significant number of them appeared in periodicals indexed in the LILACS database but not in MEDLINE. Although the LILACS database may have the advantage of showing the "hidden science" published in second-line journals (4) and not apparent in more restrictive databases such as MEDLINE and ISI, it includes a number of editorial periodicals and other publications with variable editorial policy and more 
fluid acceptance criteria.

Of the 27 LILACS-indexed journals containing papers and other communications on MS, only 7 have available IF with values ranging from 0.0217 to 0.74 (median 0.38 ). It has been pointed out that the IF has clear limitations as a measure of a journal's scientific value and that factors such as language, degree of specialization, regional location, and visibility of journals influence the accumulation of citations $(14,15)$. The IF, therefore, may rather reflect the impact of a journal in which a paper is published than its intrinsic scientific quality. In spite of these limitations, it remains a practical measure of the penetration with which a paper reaches the scientific community, therefore having a chance to modify concepts and behaviors.

The present study shows that the interest in the study of MS has increased over the years in Brazil as reflected by the increased number of papers. This growth in the field of MS is part of the increased scientific output by Brazilian investigators in other areas (4). However, most of the papers on MS have been written in Portuguese and have appeared in predominantly local medical journals with a low IF. Since MS is a disease with a much higher prevalence in the United States and Europe than in Brazil, Brazilian investigators in this field should aim at making their observations reach a broader scientific audience. We believe that adherence to stricter criteria of quality for carrying out and reporting research, attention to international editorial conventions and the use of the English language to communicate the findings should contribute to making Brazilian papers appear in journals with higher IF, and become more visible to the international scientific community.

\section{References}

1. Lana-Peixoto M, Araujo C, Macedo R, Haase VG. Studies on multiple sclerosis: the geographical distribution. Mult Scler 2002; 8 (Suppl 1): S39 (Abstract).

2. Lana-Peixoto M, Araujo C, Macedo R, Haase V, Monteiro LP. Studies on multiple sclerosis: the gross domestic product as an index of scientific productivity. Mult Scler 2004; 10 (Suppl 2): S138 (Abstract).

3. ISI - Institute for Scientific Information. Journal citation report. Philadelphia: Thomson ISI; 2003.

4. Coura JR, Willcox LC. Impact factor, scientific production and quality of Brazilian medical journals. Mem Inst Oswaldo Cruz 2003; 98 : 293-297.

5. Frame JD, Narin F. The international distribution of biomedical publications. Fed Proc 1977; 36: 1790-1795.

6. Weisinger JR, Bellorin-Font E. Latin American nephrology: scientific production and impact of the publications. Kidney Int 1999; 56: 1584-1590.

7. Kremer JA, Braat DD, Evers JL. Geographical distribution of publications in human reproduction and fertility and sterility in the 1990s. Hum Reprod 2000; 15: 1653-1656.

8. Garcia-Rio F, Serrano S, Dorgham A, Alarez-Sala R, Ruiz PA, Pino
$\mathrm{JM}$, et al. A bibliometric evaluation of European Union research of the respiratory system from 1987-1998. Eur Respir J 2001; 17: 1175-1180.

9. Grossi F, Belvedere O, Rosso R. Geography of clinical cancer research publications from 1995 to 1999. Eur J Cancer 2003; 39: 106-111.

10. Spinak E. Quantitative analyses of scientific literature and their validity for judging Latin American production. Bull Pan Am Health Organ 1995; 29: 352-359.

11. King J. A review of bibliometric and other science indicators and their role in research evaluation. $J$ Inf Sci 1987; 13: 261-276.

12. Meneghini R. Systematization of academic and scientific affiliation, or how to prevent data on your publications from being lost in the national and international data base. Braz J Med Biol Res 1995; 28 : 617-619.

13. Coimbra CE Jr. Challenges for scientific output and communications in health in Brazil. Cad Saude Publica 2003; 19: 4-5.

14. Seglen PO. Why the impact factor of journals should not be used for evaluating research. BMJ 1997; 314: 498-502.

15. Luukkonen T. Bibliometrics and evaluation of research performance. Ann Med 1990; 22: 145-150. 